\title{
New Multiband E-Shape Microstrip Patch Antenna on RT DUROID 5880 Substrate and RO4003 Substrate for Pervasive Wireless Communication
}

\author{
Dr Anubhuti Khare \\ UIT RGPV Bhopal
}

\author{
Rajesh Nema \\ NIIST Bhopal \\ Rajeev Kumar Thakur \\ NIIST Bhopal
}

\author{
Puran Gour \\ NIIST Bhopal
}

\begin{abstract}
The area of micro strip antennas has seen some inventive work in recent years and is currently one of the most dynamic fields of antenna theory. An overview of work done in the area of micro strip antennas is presented and several recent developments in the field are highlighted. In addition, new antenna configurations that improve electrical performance and manufacturability are described. This designing is very easy and chip in microstrip antenna designing. We analyzed micro strip antenna in IE3D by finite moment of method. The proposed antenna design on different substrate and analyzed result of both substrates between $1 \mathrm{GHz}$ to $20 \mathrm{GHz}$, When the proposed antenna design on a $31 \mathrm{mil}$ RT DUROID 5880 substrate from Rogers-Corp with dielectric constant of 2.2 and loss tangent of .004 . At $14 \mathrm{GHz}$ the verify and tested result on IE3D SIMULATOR are Return loss $=-10.35 \mathrm{~dB}$, VSWR $=1.872, \quad$ Directivity $=6 \mathrm{dbi}, \quad \mathrm{Z}=32.94 \Omega \quad$ Characteristic impedance, and when The proposed antenna design on a 60 mil RO4003 substrate from Rogers-Corp with dielectric constant of 3.4 and loss tangent of .002 . At $10 \mathrm{GHz}$ the effective results of RO4003 substrate verify and tested on IE3D SIMULATOR are Return loss $=-21.34 \mathrm{~dB}, \quad$ VSWR $=1.192$, Directivity $=8 \mathrm{dbi}$, $\mathrm{Z}=42.31 \Omega$ Characteristic impedance, Axial ratio (at theta $=90 \mathrm{deg}$ ) $=96 \%$. The optimum 60 mil RO4003 substrate E Shape microstrip patch antenna provides very good results between $10 \mathrm{GHz}$ to $20 \mathrm{GHz}$, All results shown in Simulation results. The results shown in Table 1, Table2,
\end{abstract}

\section{Keywords}

Micro strip antenna, IE3D SIMULATOR, Dielectric, Patch width, Patch Length, Characteristic Impedance, Losses, strip width, strip length

\section{INTRODUCTION}

A A Deshmukh and G Kumar [9] proposed compact L Shape patch broadband Microstrip antenna experimentally increase bandwidth up to $13.7 \%$. Z M Chen [14] further increase bandwidth of this antenna up to $23.7 \%-24.4 \%$. J George [3] proposed optimal angle between feed line and patch for enhancing bandwidth. K F Lee [14] proposed U Shape slot shorting post small size Microstrip Antenna and increase bandwidth up to $42 \%$. Z M chen Tsai K F Lee [14] [13] used low permittivity in proposed design for enhancing Bandwidth. $\mathrm{R}$ Garg P Bharti [10] significant increasing in bandwidth by increasing height of dielectric material. Latif S I Shafai [2] enhances gain and bandwidth by novel technique form ring by depositing multiple conductor layer separated by laminating dielectric. S C Gao [8] used uniplanar photonic band gap structure for enhancing band width and gain. M Khodier[11] New wideband stacked microstrip antennas for enhancing band width. W. S. Yun, Wideband microstrip antennas for PCS/IMT2000 services. Major issue for microstrip antenna is narrow Bandwidth. Our proposed 31 mil RT DUROID 5880 substrate E shaped antenna provides optimum results at $14 \mathrm{GHz}$ VSWR is 1.872 and return loss is $-10.35 \mathrm{~dB}$. and proposed $60 \mathrm{mil}$ RO4003 substrate $\mathrm{E}$ shaped antenna provide optimum results between $10 \mathrm{GHz}-20 \mathrm{GHz}$. at $10 \mathrm{GHz}$ VSWR is 1.192 and return loss is $21.34 \mathrm{~dB}$. The results of proposed E-Shaped Multiband microstrip patch antenna verified in IE3D Simulator.All results shown in simulation result..We find mathematical analysis of micro strip given below

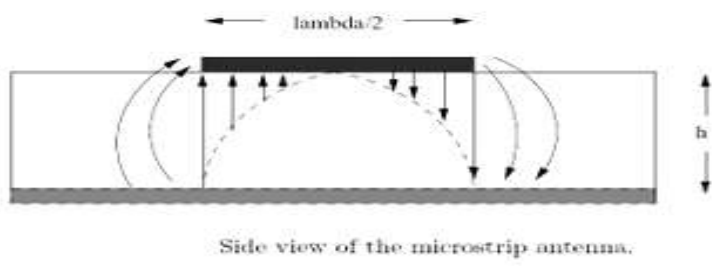

Figure 1

\section{EFFECTIVE PARAMETERS}

The electric field radiated from a micro strip antenna meets a boundary between two different dielectrics: air and the substrate material. Because of the slight distortion of the field at the boundary, the patch can appear longer in an electrical sense. Thus we have an effective patch length. There is also an effective relative permittivity when performing micro strip antenna analysis. The effective relative permittivity can be calculated by this formula used widely in

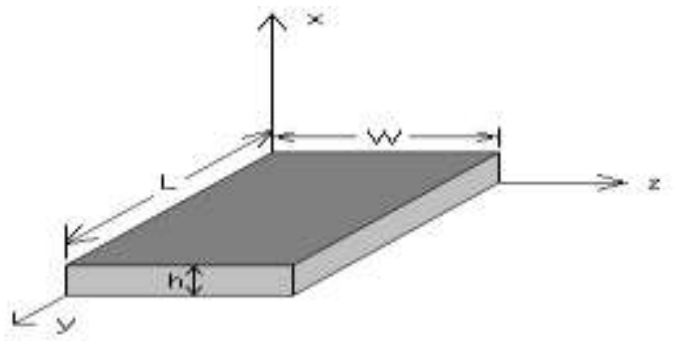




\section{E-plane pattern}

$$
\mathrm{E}_{\Phi}=\frac{\mathrm{kV}_{0} \mathrm{w}}{2 \pi \mathrm{r}} e^{-j k r}\left[\sin \theta\left(\frac{\sin \left(\frac{\mathrm{kW}}{2} \cos \theta\right)}{\frac{\mathrm{kW}}{2} \cos \theta}\right)\right]
$$

H-plane pattern

$H_{\theta}=\mathrm{E}_{\Phi} / \eta$

Characteristic impedance of microstrip line feed for $\mathbf{w} / \mathbf{h} \leq 1$

$$
\mathrm{Z}_{0}=\frac{60}{\sqrt{\varepsilon_{\text {reff }}}} \ln \left[\frac{8 h}{\mathrm{w}}+\frac{\mathrm{w}}{4 h}\right]
$$

for

$\mathbf{w} / \mathbf{h}$

$\geq 1$

$$
\mathrm{Z}_{0}=\frac{120 \pi}{\sqrt{\varepsilon_{\text {reff }}}\left[\frac{\mathrm{w}}{h}+1.393+.667 \ln \left(\frac{\mathrm{w}}{h}+1.44\right)\right]}
$$

Beam widths E-plane

$$
\theta \mathbf{E} \cong 2 \cos ^{-1} \sqrt{\frac{7.03 \lambda 0^{2}}{4\left(3 L e^{2}+h^{2}\right) \pi^{2}}}
$$

H-plane

$$
\theta_{H} \cong 2 \cos ^{-1} \sqrt{\frac{1}{2+k w}}
$$

Transmission line method is the easiest method as compared to the rest of the methods. This method represents the rectangular micro strip antenna as an array of two radiating slots, separated by a low impedance transmission line of certain length.

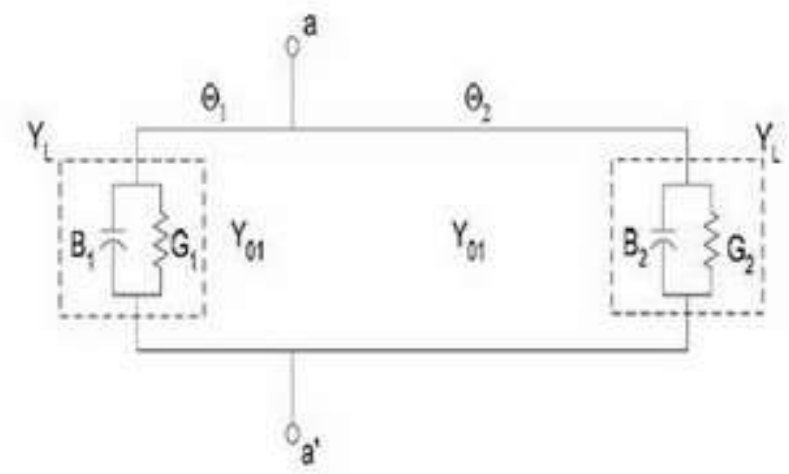

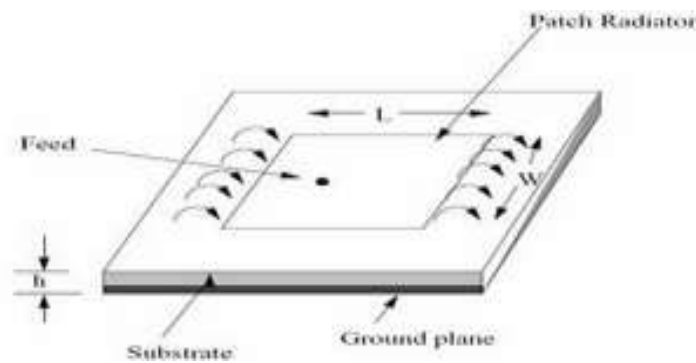

Figure 2

The above Figure 3 shows a patch antenna from the Transmission Line Model perspective. We can observe the fringing at the edges increasing the effective length.

$$
\begin{aligned}
& \varepsilon_{\text {reff }}=\frac{(\varepsilon \mathrm{r}-1)}{2}+\frac{(\varepsilon \mathrm{r}+1)}{2}\left(1+10 \frac{\mathrm{h}}{\mathrm{W}}\right)^{-1 / 2} \\
& \mathrm{~W}=\frac{\mathrm{c}}{2 f_{r}} \sqrt{\frac{2}{\varepsilon_{\mathrm{r}}+1}}
\end{aligned}
$$

\section{PROPOSED ANTENNA AT 14GHz ON 31 mil RT DUROID 5880 substrate}

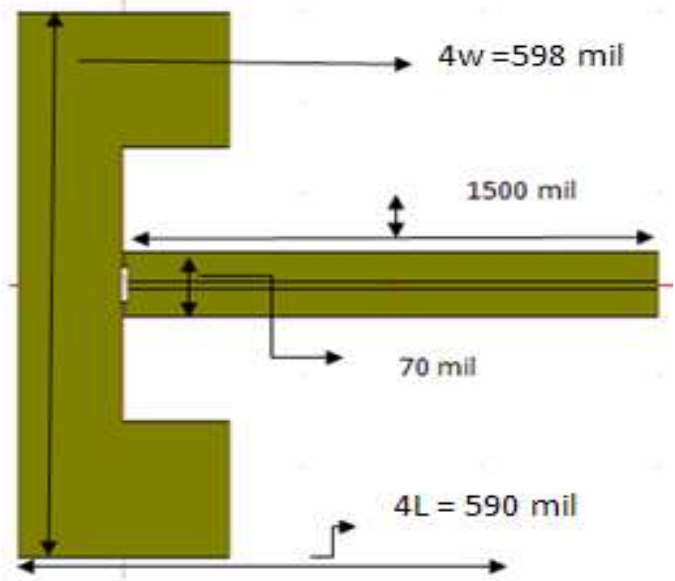

The Proposed antenna has:-

Proposed Patch length $=4 \mathrm{~L}$

Proposed Patch Width $=4 \mathrm{~W}$

Strip Path Length $=1500 \mathrm{miles}$

Strip Path Width $=70 \mathrm{miles}$

Cut width $=300 \mathrm{miles}$

Cut depth $=300$ miles

$\mathbf{w}=\frac{\mathrm{c}}{2 f_{r}} \sqrt{\frac{2}{\varepsilon_{\mathrm{r}}+1}}$ 


\section{PROPOSED ANTENNA AT 10GHz $60 \mathrm{mil}$} RO4003 substrate

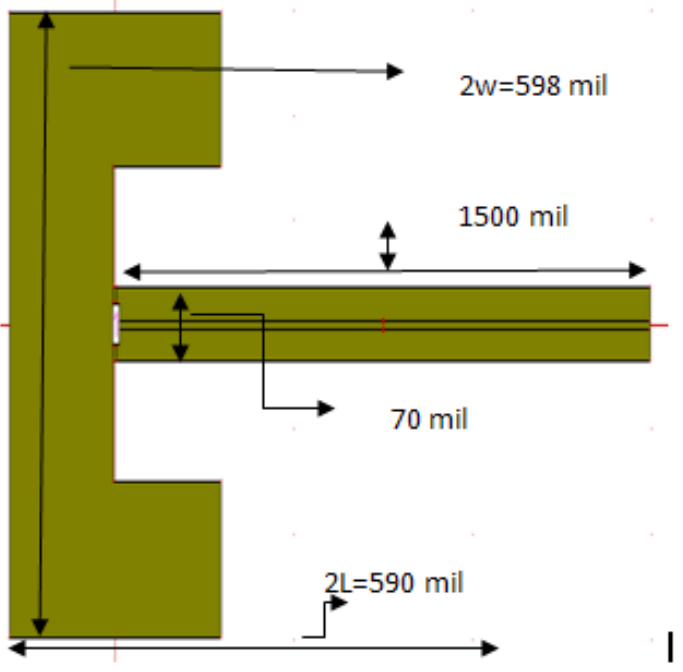

The Proposed antenna has:-

Proposed Patch length $=2 \mathrm{~L}$

Proposed Patch Width $=2 \mathrm{~W}$

Strip Path Length $=1500 \mathrm{miles}$

Strip Path Width $=70 \mathrm{miles}$

Cut width $=300 \mathrm{miles}$

Cut depth $=300$ miles

SIMULATED MICROSTRIP PATCH ANTENNA IN IE3D SIMULATOR FOR $31 \mathrm{mil}$ RT DUROID 5880 SUBSTRATE AND 60 mil RO4003 SUBSTRATE

(1) VSWR VS FREQUENCY (IN GHz)

\section{(a) RT DUROID 5880 substrate}

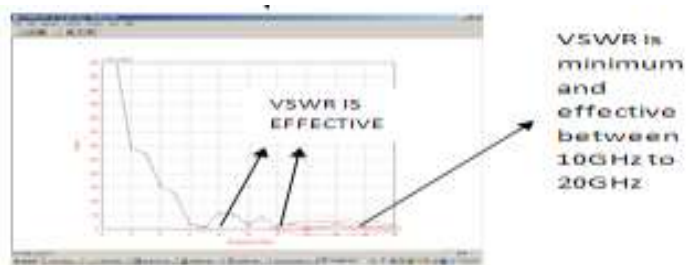

For

proposed design the value of VSWR is effective between $14 \mathrm{GHz}$ to $20 \mathrm{GHz}$, for this value return loss is minimum. At $14 \mathrm{GHz}$ return loss is $-10.35 \mathrm{~dB}$ and VSWR is 1.872 , At $7 \mathrm{GHz}$ VSWR is 3.581, At $12 \mathrm{GHz}$ VSWR is 4.712 , at $15 \mathrm{GHz}$ VSWR is 5.197 , at $17 \mathrm{GHz}$ VSWR is 7.404 , at $18 \mathrm{GHz}$ VSWR is 3.931 , at $20 \mathrm{GHz}$ VSWR is 5.683

(b) $\underline{\mathrm{RO4003} \text { substrate }}$

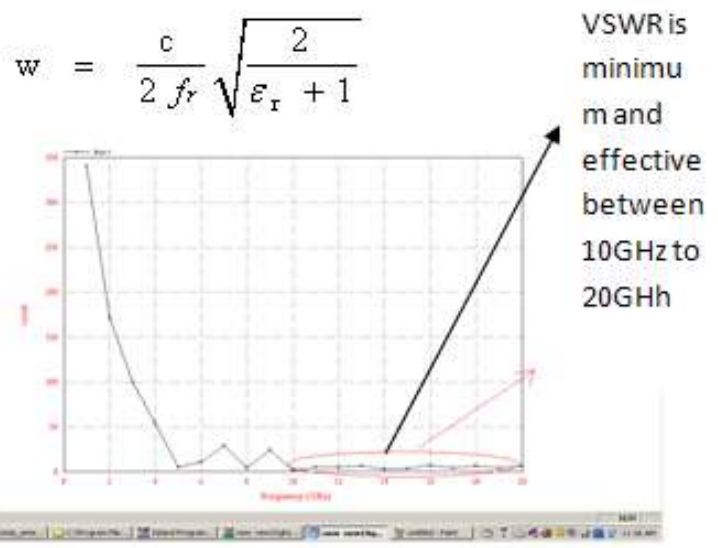

For proposed design the value of VSWR is very effective between $10 \mathrm{GHz}$ to $20 \mathrm{GHz}$, for this value return loss is minimum. At $10 \mathrm{GHz}$ return loss is $-21.34 \mathrm{~dB}$ and VSWR is 1.192 , At $14 \mathrm{GHz}$ VSWR is 2.678 , At $15 \mathrm{GHz}$ VSWR is 3.013 , at $8 \mathrm{GHz}$ VSWR is 3.7 , at $19 \mathrm{GHz}$ VSWR is 3.686 , at $5 \mathrm{GHz}$ VSWR is 4.468

\section{(2) Directivity VS FREQUENCY (IN GHz)}

(a) RT DUROID 5880 substrate

Directivity vs frequency

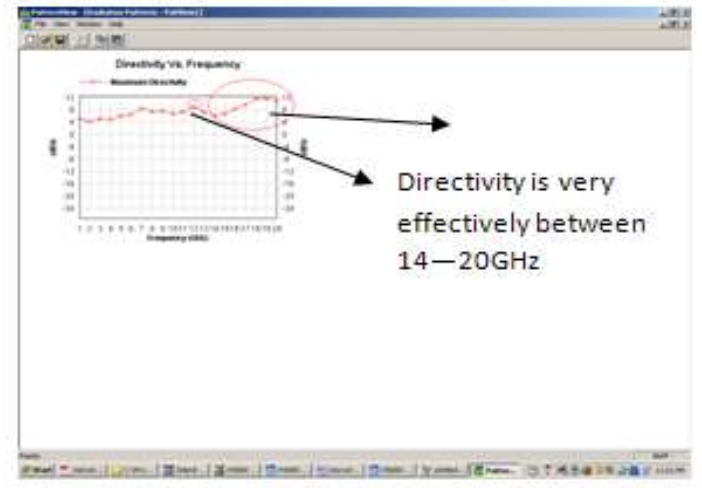

At $14 \mathrm{GHz}$ Directivity is $6 \mathrm{dBi}$, between $18-20 \mathrm{GHz}$ Directivity is $11 \mathrm{dBi}$, at $17 \mathrm{GHz}$ Directivity is $9 \mathrm{dBi}$,

(b) $\underline{\text { RO4003 substrate }}$

Directivity vs frequency

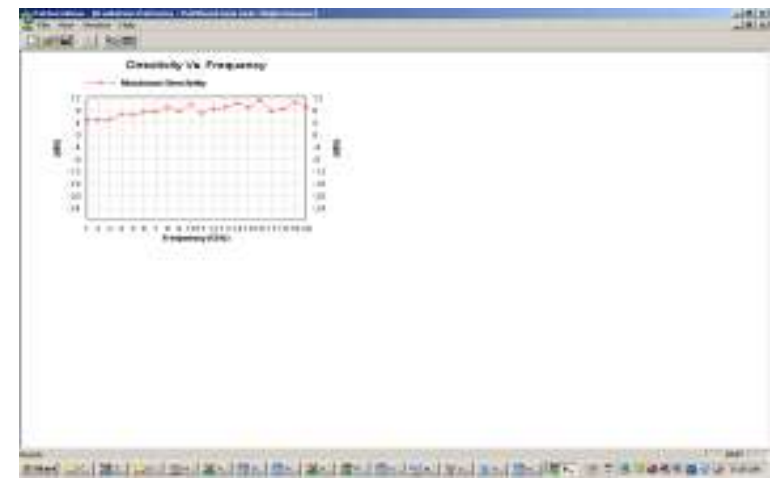




\section{(3) Return loss VS Frequency (in GHz)}

(a) RT DUROID 5880 substrate

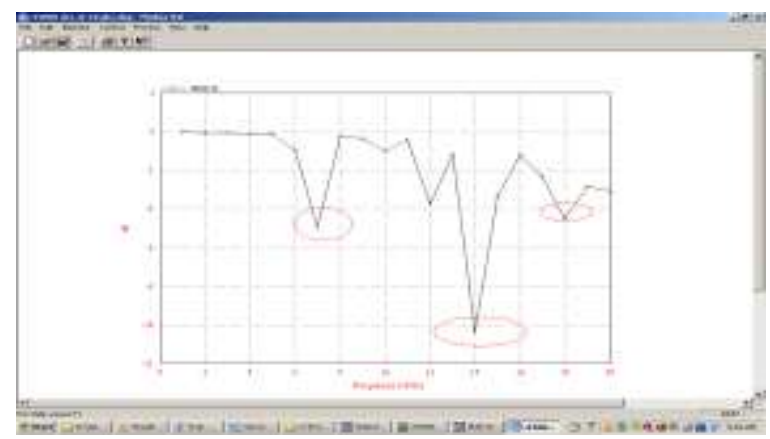

The frequency at $7 \mathrm{GHz}$ return losses is -4.983 , at $12 \mathrm{GHz}$ return losses is $\mathbf{- 3 . 7 4 4}$, at $14 \mathrm{GHz}$ return losses reduce very significantly $\mathbf{- 1 0 . 3 5}$, at $15 \mathrm{GHz}$ return loss is -3.385 , at $18 \mathrm{GHz}$ return loss is $\mathbf{- 4 . 5 1 9}$

(b) $\underline{\text { RO4003 substrate }}$

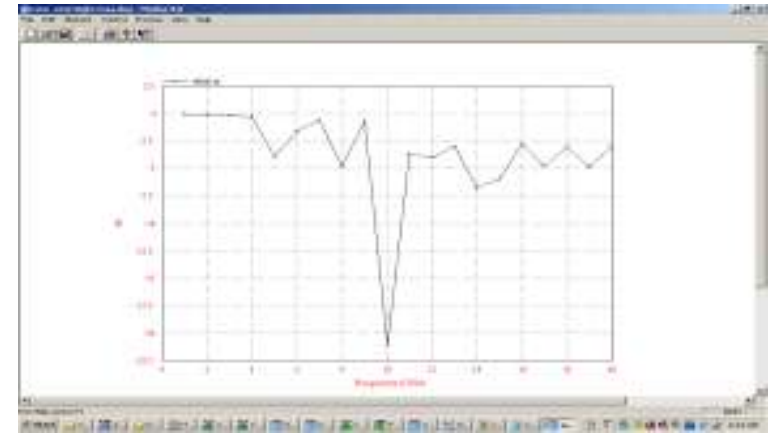

frequency at $5 \mathrm{GHz}$ return losses is $\mathbf{- 3 . 9 5 5}$, at $8 \mathrm{GHz}$ return losses is -4.789 , at $10 \mathrm{GHz}$ return losses reduce very significantly -21.34 , at $14 \mathrm{GHz}$ return loss is -6.816 , at $15 \mathrm{GHz}$ return loss is $\mathbf{- 5 . 9 9 2}$

(4) $S$ Parameter (magnitude in $d b$ and phase) VS Frequency in $\mathrm{GHz}$

(a) RT DUROID 5880 substrate

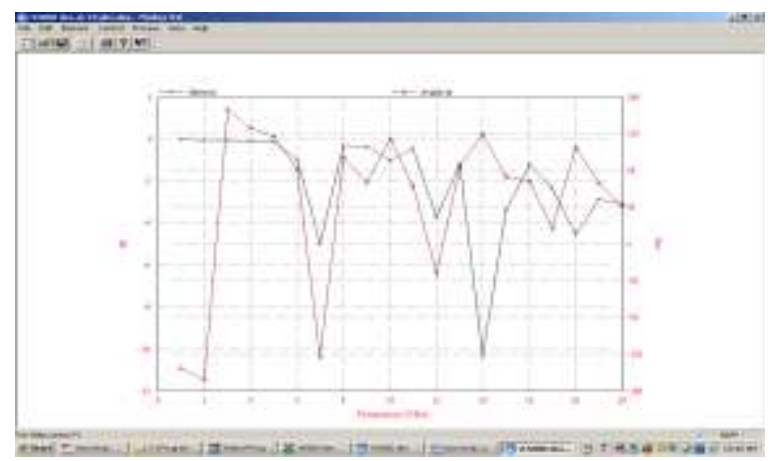

(b) $\underline{\text { RO4003 substrate }}$

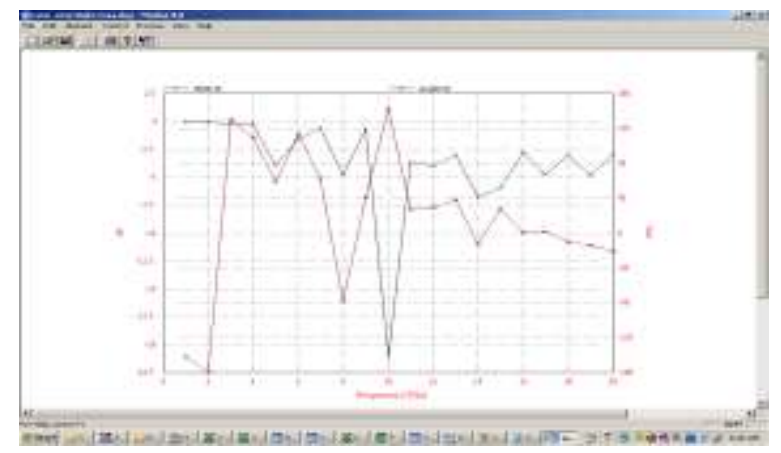

(5) SIMTH CHART FOR DIFFERENT MEASURMENT

(a) RT DUROID 5880 substrate

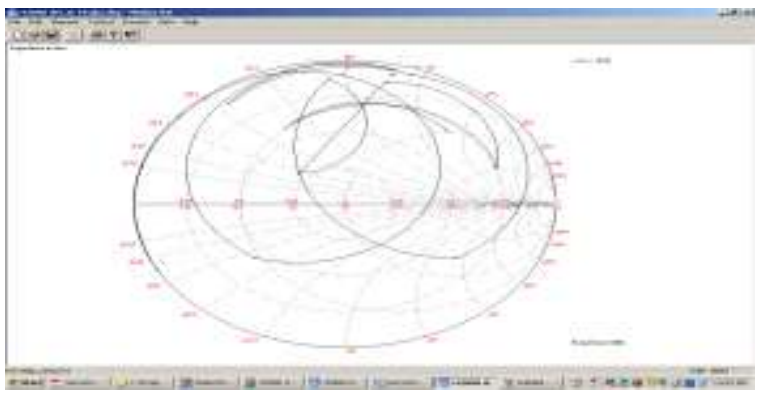

(b) $\underline{\mathrm{RO4003} \text { substrate }}$

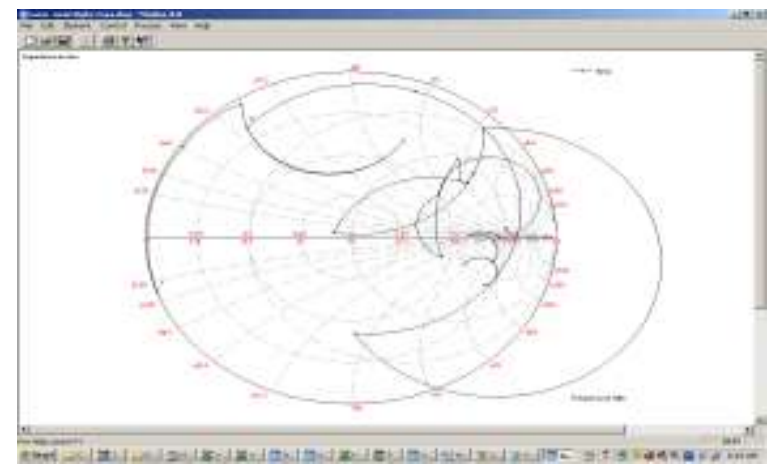

(6) (Antenna Efficiency and Radiating Efficiency) VS (Frequency in GHz)

(a) RT DUROID 5880 substrate

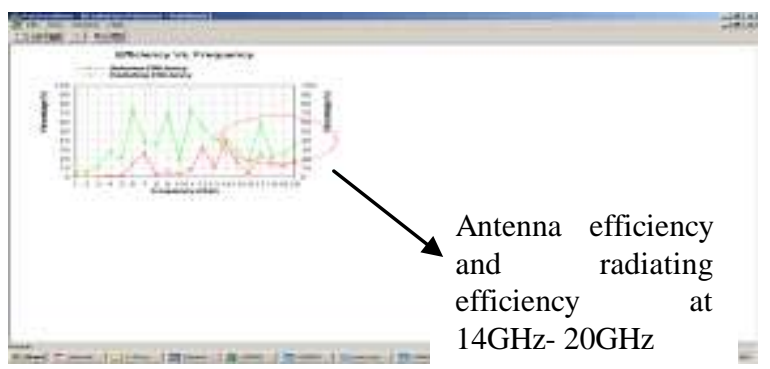




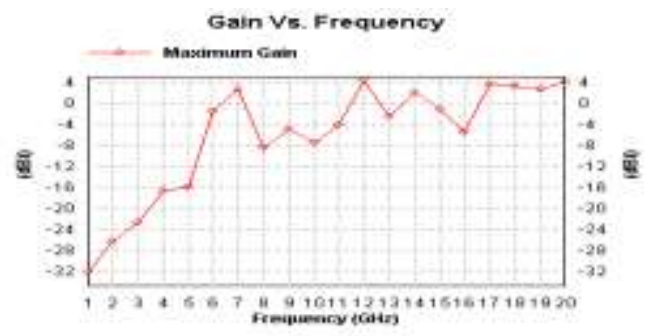

(b)

\section{$\underline{\text { RO4003 substrate }}$}

\section{Gain vs frequency}

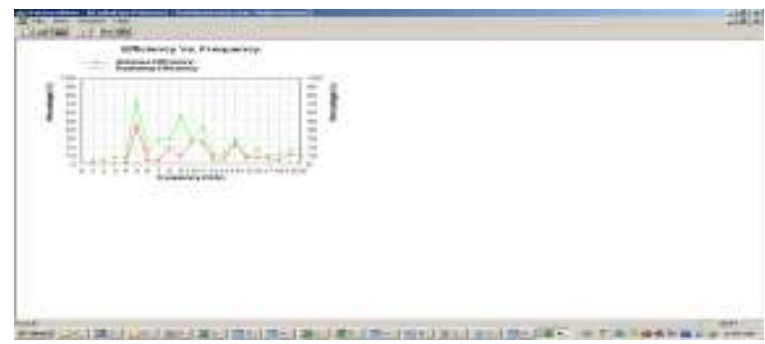

\section{(7) Radiation Pattern:-}

(i) RT DUROID 5880 substrate

Study of different Azimuth pattern and Elevation pattern in IE3D .Analyzed radiation characteristic of antenna at 10 GHz shown in figure

(a) Elevation Pattern

Elevation Pattern of E maximum,

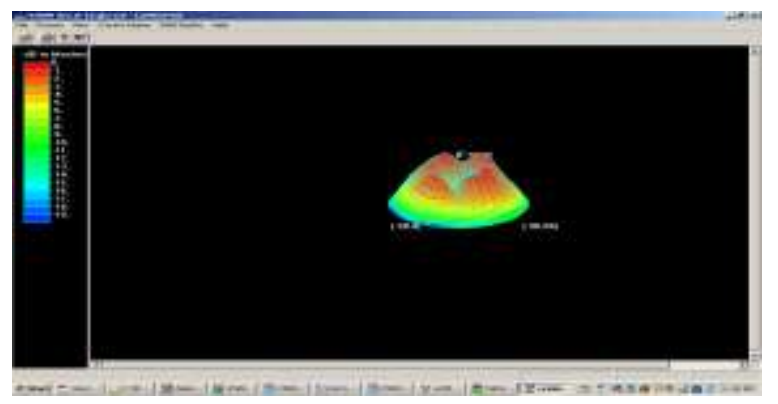

E Theta at phi $=0$ deg

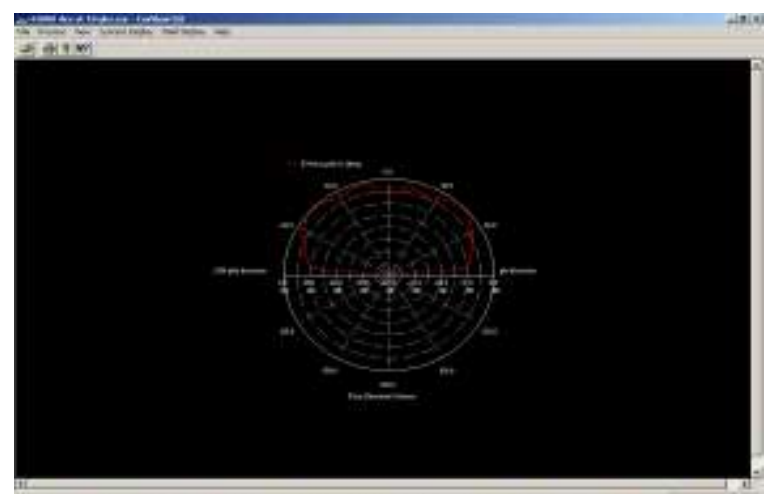

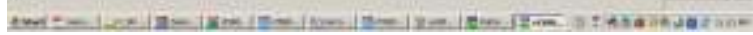

Elevation Pattern of $\mathbf{E}$ Total at phi $=90(\mathrm{deg})$

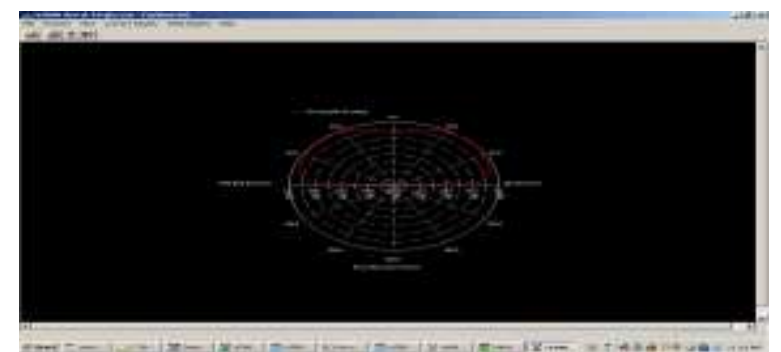

Elevation Pattern of E Total, E Right, E left, E theta, E Phi at phi $=90$ (deg)

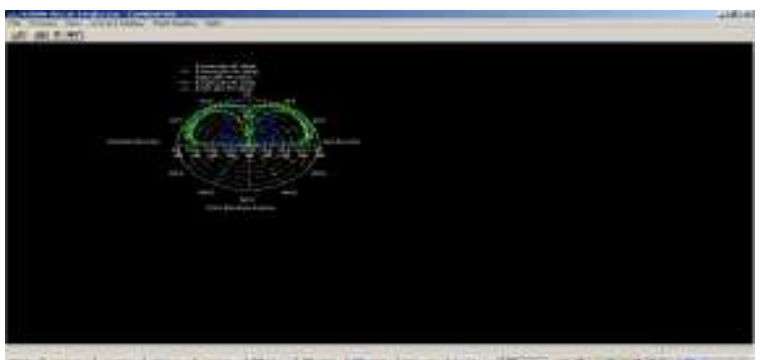

(b) Azimuth Pattern

Azimuth Pattern at E theta, theta=0(deg)

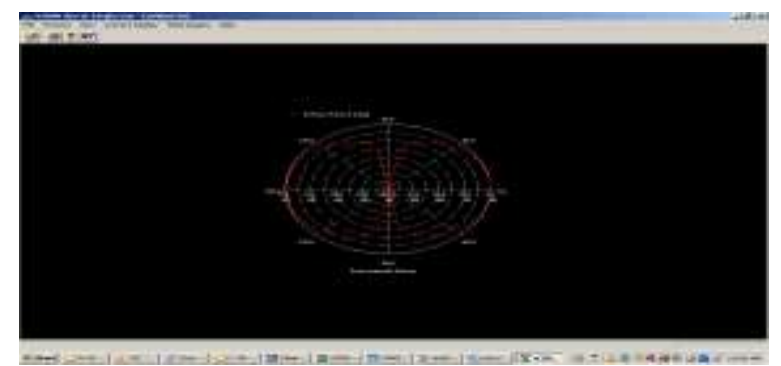

Azimuth Pattern of E Total at theta=90(deg)

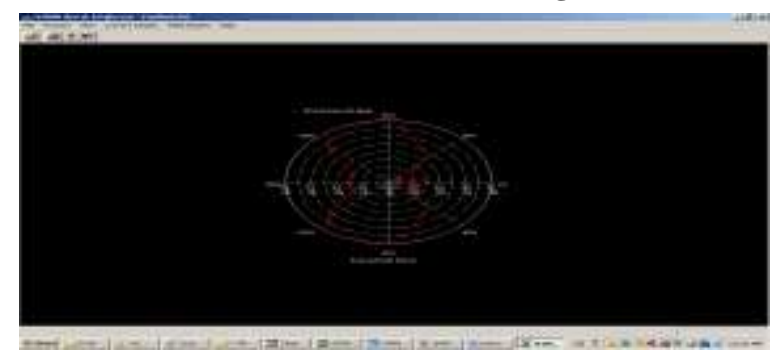

Azimuth Pattern of E Total at theta=45(deg)

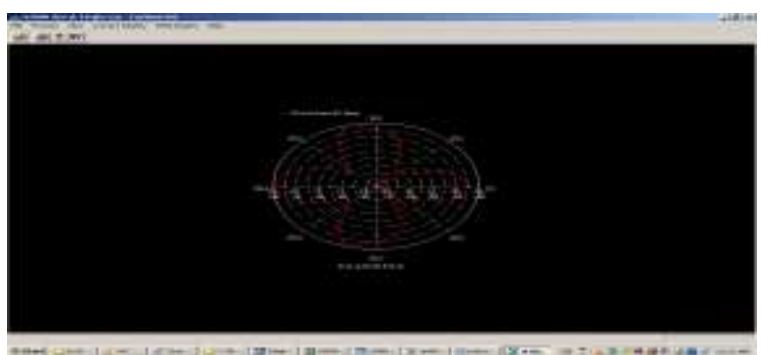


Azimuth Pattern of E Total, E Right, E left, E theta, E Phi at theta $=90($ deg $)$

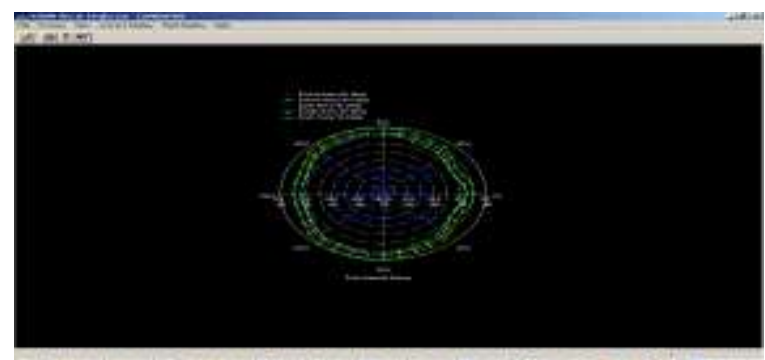

(8)AXIAL RATIO PATTERN

\section{(A) FOR AZIMUTH PATTERN}

Axial Pattern at theta $=0(\mathrm{deg})$

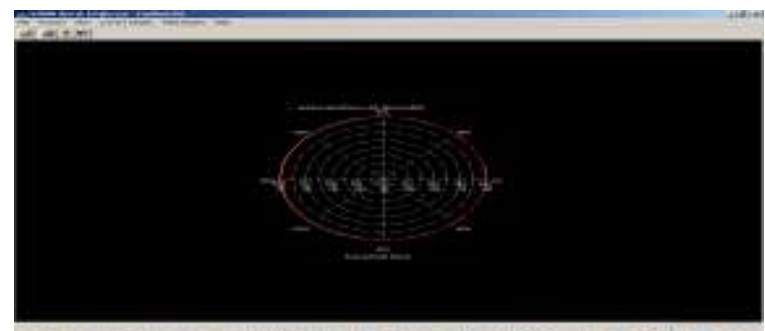

(B)FOR ELEVATION PATTERN

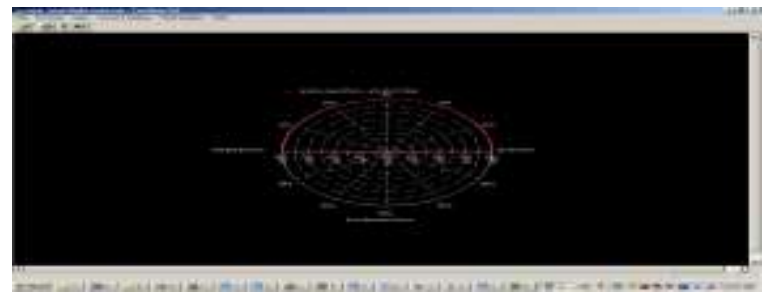

Axial Pattern at $\mathbf{P h i}=\mathbf{5 0}(\mathrm{deg})$

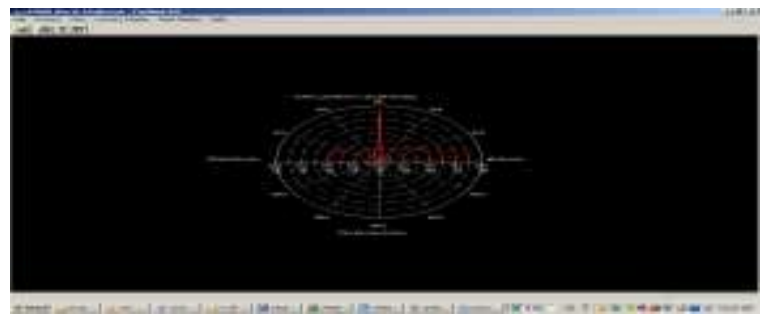

Axial Pattern at Phi $=90(\mathbf{d e g})$

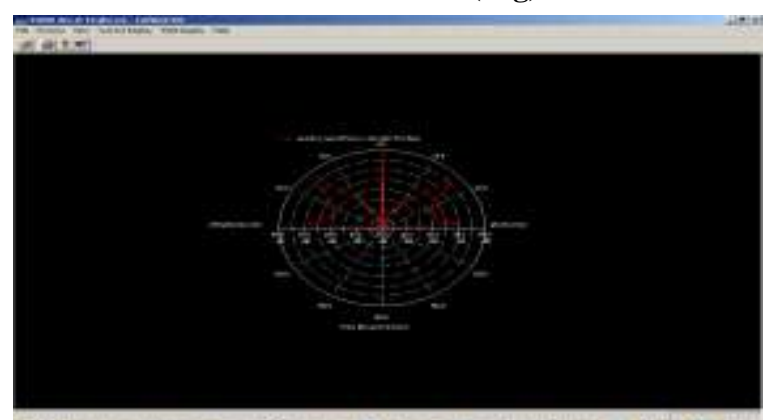

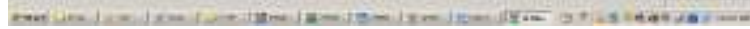

\section{Axial ratio vs. Frequency}

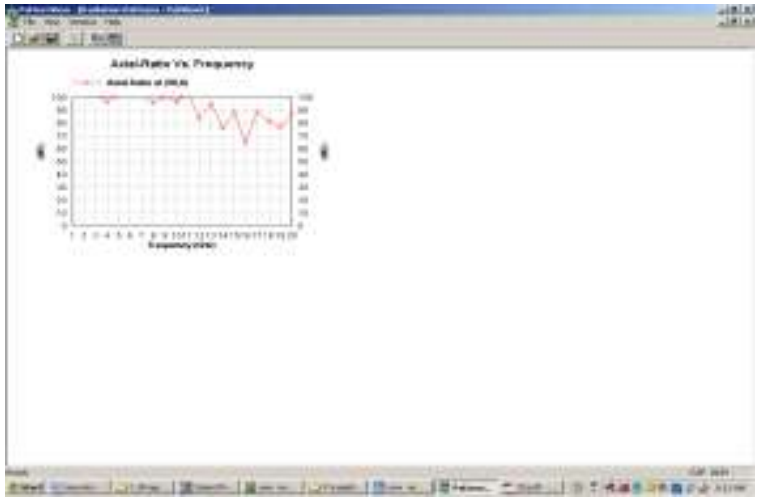

3D Elevation Pattern at $90 \mathrm{deg}$

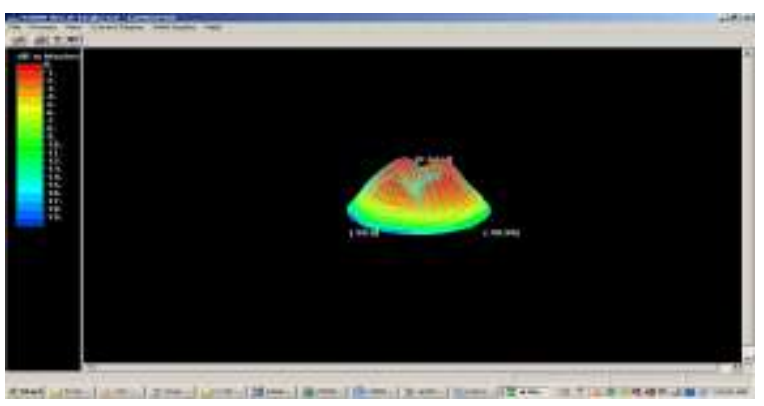

Current density distribution for proposed design

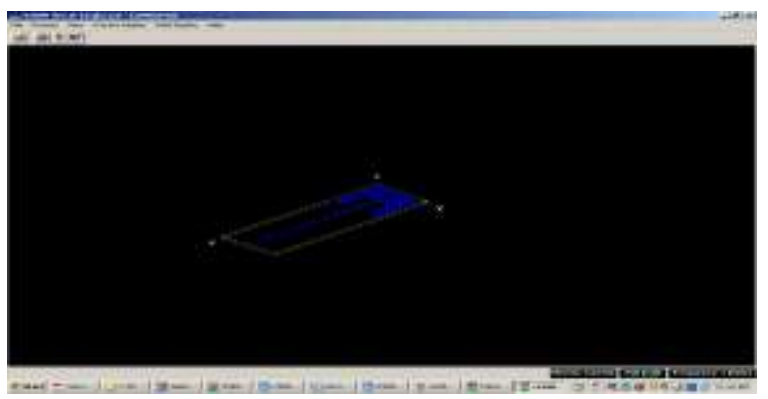

$\underline{\text { Radiation Pattern }}$

(ii) $\underline{\mathrm{RO} 4003}$ substrate

Study of different Azimuth pattern and Elevation pattern in IE3D .Analyzed radiation characteristic of antenna at 10 GHz shown in figure

(a) Elevation Pattern

Elevation Pattern of E Total, E Right, E left, E theta, E Phi at phi $=0$ (deg)

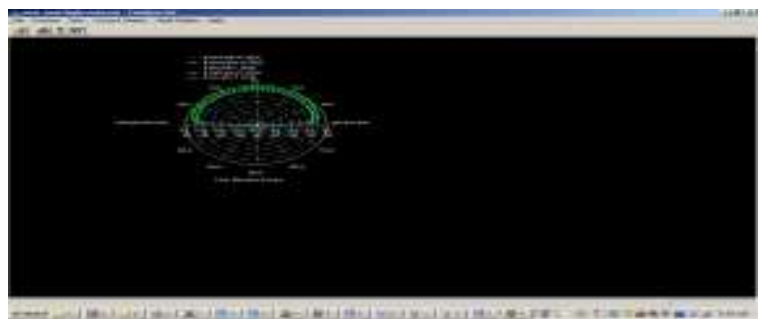


Elevation Pattern of E Total, E Right, E left, E theta, E Phi at phi=90 (deg)

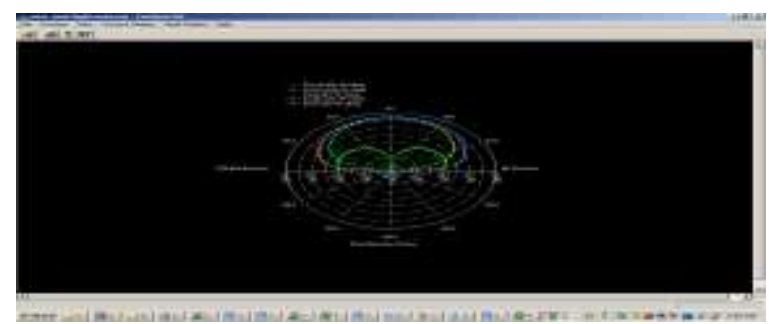

(b) Azimuth Pattern

Azimuth Pattern of E Total, E Right, E left, E theta, E Phi at theta $=90(\mathrm{deg})$

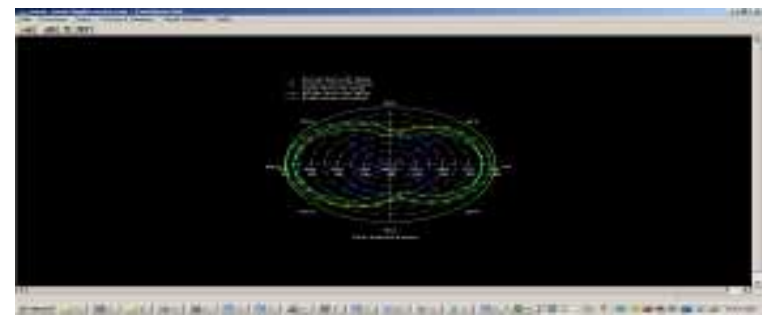

Axial Ratio pattern at theta $=20(\mathrm{deg})$

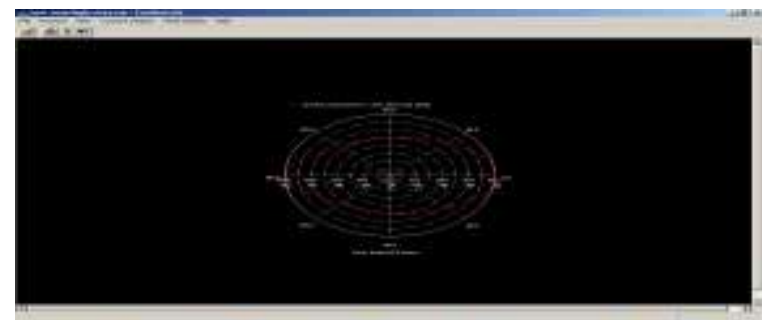

Azimuth Pattern at theta $=90(\mathrm{deg})$

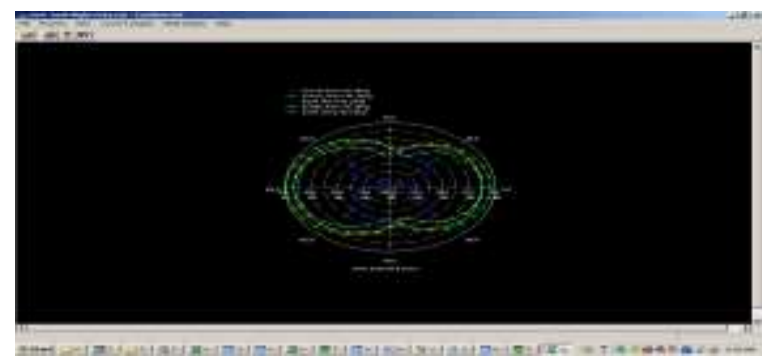

Current density distribution for proposed design

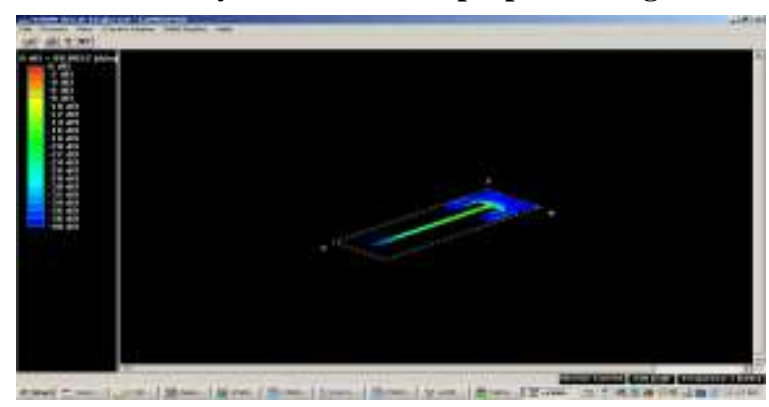

(b) $\underline{\text { RO4003 substrate }}$

Axial ratio vs. Frequency

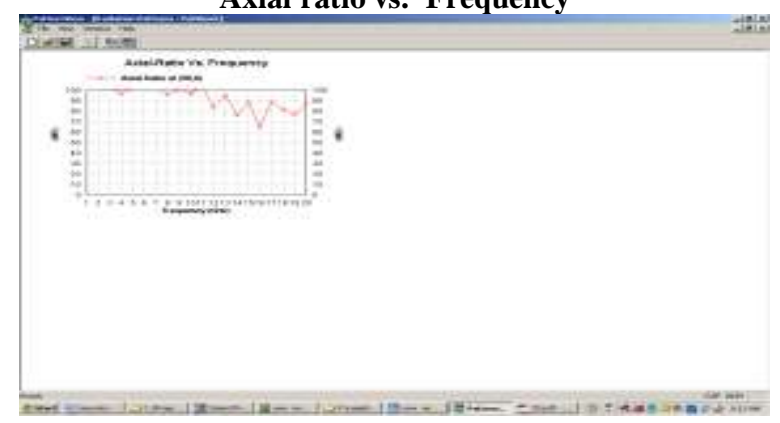

Axial ratio at $10 \mathrm{GHz}$ is $96 \%$ verify in IE3D SIMULATOR

\section{Simulation Table:-}

Table -1 dB [S (i j)] in dB and Ang[S (i j)] in Deg

\begin{tabular}{|c|c|c|}
\hline $\begin{array}{l}\text { Freq } \\
\text { [Ghz] }\end{array}$ & $\begin{array}{lr}\mathrm{dB}[\mathrm{S}(1,1)] & 31 \\
\text { mil } & \mathrm{RT} \\
\text { DUROID } & \mathbf{5 8 8 0} \\
\text { substrate } & \end{array}$ & $\begin{array}{l}\mathrm{dB}[\mathrm{S}(1,1)] \quad 60 \\
\text { mil RO4003 } \\
\text { substrate }\end{array}$ \\
\hline 1 & $-2.912 \mathrm{e}^{-0.02}$ & $-5.1 \mathrm{e}^{-0.02}$ \\
\hline 2 & $-5.98 \mathrm{e}^{-0.02}$ & -0.1011 \\
\hline 3 & $-6.412 \mathrm{e}^{-0.02}$ & -0.1752 \\
\hline 4 & -0.1106 & -0.3228 \\
\hline 5 & -0.1389 & -3.955 \\
\hline 6 & -0.9716 & -1.604 \\
\hline 7 & -4.983 & -0.6102 \\
\hline 8 & -0.3035 & -4.789 \\
\hline 9 & -0.3481 & -0.7328 \\
\hline 10 & -1.037 & -21.14 \\
\hline 11 & -0.4362 & -3.673 \\
\hline 12 & -3.744 & -4.01 \\
\hline 13 & -1.181 & -3.038 \\
\hline 14 & -10.35 & -6.816 \\
\hline 15 & -3.385 & -5.992 \\
\hline 16 & -1.22 & -2.819 \\
\hline 17 & -2.361 & -4.79 \\
\hline 18 & -4.519 & -3.06 \\
\hline 19 & -2.868 & -4.833 \\
\hline 20 & -3.089 & -2.95 \\
\hline
\end{tabular}


Table -2 Frequency (GHz) vs. VSWR (MEASUREMENT BY IE3D SIMULATOR)

\begin{tabular}{|c|c|c|}
\hline $\begin{array}{l}\text { Frequency } \\
\text { [GHz] }\end{array}$ & $\begin{array}{lr}\text { VSWR } & 31 \\
\text { mil RT } \\
\text { DUROID } \\
\text { 5880 } \\
\text { substrate }\end{array}$ & $\begin{array}{l}\text { VSWR } \\
60 \quad \text { mil } \\
\text { RO4003 } \\
\text { substrate }\end{array}$ \\
\hline 1 & 596.5 & 340.6 \\
\hline 2 & 290.5 & 171.8 \\
\hline 3 & 270.9 & 99.18 \\
\hline 4 & 157.1 & 53.83 \\
\hline 5 & 125.1 & 4.468 \\
\hline 6 & 17.9 & 10.68 \\
\hline 7 & 3.581 & 28.48 \\
\hline 8 & 57.24 & 3.719 \\
\hline 9 & 49.91 & 23.72 \\
\hline 10 & 16.77 & 1.192 \\
\hline 11 & 39.83 & 4.8 \\
\hline 12 & 4.712 & 4.409 \\
\hline 13 & 14.73 & 5.776 \\
\hline 14 & 1.872 & 2.678 \\
\hline 15 & 5.197 & 3.013 \\
\hline 16 & 14.26 & 6.215 \\
\hline 17 & 7.404 & 3.718 \\
\hline 18 & 3.931 & 5.736 \\
\hline 19 & 6.111 & 3.686 \\
\hline 20 & 5.683 & 5.946 \\
\hline
\end{tabular}

\section{CONCLUSION}

Microstrip antennas have become a rapidly growing area of research. Their potential applications are limitless, because of their light weight, compact size, and ease of manufacturing. One limitation is their inherently narrow bandwidth. However, recent studies and experiments have found ways of overcoming this obstacle. A variety of approaches have been taken, including modification of the patch shape, experimentation with substrate parameters, Most notably mobile communication systems where many frequency ranges could be accommodated by a single antenna. We here design simple and low costlier patch antenna for pervasive wireless communication by using different substrate. The transmission line model seems to be the most instructive in demonstrating the bandwidth effects of the changing the various parameters. When the proposed antenna design on a 31 mil RT DUROID 5880 substrate from RogersCorp with dielectric constant of 2.2 and loss tangent of .004. The proposed antenna has four times patch length, four times patch width and more feed line length. The proposed frequency range $14 \mathrm{GHz}(\mathrm{Ku}$ Band) and Analysis Radiation Characteristics of micro strip Antenna by IE3D Simulator. The results of proposed designing are effective between $14 \mathrm{GHz}-20 \mathrm{GHz}$. proposed antenna simulated in IE3D Simulator. The optimum results of proposed antenna verify and tested in IE3D SIMULATOR. The simulated results of IE3D at $14 \mathrm{GHz}$ is Return loss $=-10.35 \mathrm{db}$, VSWR $=1.872$, Directivity $=8 \mathrm{dbi}$. The proposed $31 \mathrm{mil}$ RT DUROID 5880 substrate E-Shaped multiband microstrip antenna effective work on $7 \mathrm{GHz}, 12 \mathrm{GHz}$, at $14 \mathrm{GHz}$ ( $\mathrm{Ku}$ Band) the proposed antenna work very effectively for pervasive wireless communication. When the proposed antenna design on a $60 \mathrm{mil}$ RO4003 substrate from Rogers-Corp with dielectric constant of 3.4 and loss tangent of .002. The proposed frequency range $10 \mathrm{GHz}$ (X Band) and Analysis Radiation Characteristics of micro strip Antenna by IE3D Simulator. The proposed antenna has double patch length, patch width and more feed line length. The results of proposed designing are very effective between $10 \mathrm{GHz}$ 20GHz. proposed antenna simulated in IE3D Simulator. The optimum results of proposed antenna verify and tested in IE3D SIMULATOR. The simulated results of IE3D at $10 \mathrm{GHz}$ is Return loss $=-21.34 \mathrm{db}$, VSWR $=1.192$, Directivity $=8 \mathrm{dbi}$. Axial ratio is $96 \%$. The proposed 60mil RO4003 substrate E-Shaped multiband microstrip antenna effective work on $5 \mathrm{GHz}, 8 \mathrm{GHz}$, and between $(10 \mathrm{GHz}-20 \mathrm{GHz})$ Band for pervasive wireless communication.

\section{REFERENCES}

[1] Design considerations for rectangular rmicrostrip patch antenna on electromagnetic crystal substrate at terahertz frequency Infrared Physics \& Technology, Volume 53, Issue 1, January 2010, Pages 17-22 G. Singh

[2] Latif, S.I. Shafai, L. Shafai, C. Dept. of Electr. \& Comput. Eng., Univ. of Manitoba, Winnipeg, MB "Ohmic loss reduction and gain enhancement of microstrip antennas using laminated conductors "Antenna Technology and Applied Electromagnetics and the Canadian Radio Science Meeting, 2009. ANTEM/URSI2009. 13th International Symposium on Toronto,

[3] 2009 WRI International Conference on Communications and Mobile Computing Improved Microstrip Fractal Patch Antenna Using Uni-planar Compact Photonic Bandgap Structure (UC-PBG) January 06-January 08 Gao Wei Deng Hui

[4] Progress in Electromagnetics Research Symposium Proceedings, Moscow, Russia, August 18\{21, 20091087 Annular Ring Micro strip Patch Antenna on a Double Dielectric Anisotropic Substrate C. F. L. Vasconcelos1, S. G. Silva1, M. R. M. L.Albuquerque1, J. R. S. Oliveira2, and A. G. d'Assun»c $\sim$ aol

[5] Abbaspour,M. and H. R. Hassani, Wideband star-sharped microstrip patch antenna,"Progress In Electromagnetic Research Letters, Vol. 1, 61\{68, 2008.

[6] Sabri, H. and Z. Atlasbaf, ITwo novel compact triple-band micro strip annular-ring slot antenna for PCS-1900 and 
WLAN applications," Progress In Electromagnetics Research Letters, Vol. 5, 87\{98, 2008

[7] A.Shackelford, K. F. Lee, D. Chatterjee, Y. X. Guo, K. M. Luk, and R. Chair,"Small size wide bandwidth microstrip patch antennas," in IEEE Antennas and Propagation International Symposium, vol. 1, (Boston, Massachusetts), pp. 86-89,IEEE, July 2001.

[8] S. C. Gao, L. W. Li, M. S. Leong, and T. S. Yeo, "Design and analysis of a novel wideband microstrip antenna," in IEEE Antennas and Propagation International Symposium,vol. 1, (Boston, Massachusetts), pp. 90-93, IEEE, July 2001.

[9] A.A.Deshmukh and G. Kumar, "Compact broadband gapcoupled shorted L-shaped microstrip antennas," in IEEE Antennas and Propagation International Symposium, vol 1, (Baltimore, Maryland), pp. 106-109, IEEE, July 2001.

[10] R. Garg, P. Bhartia, I. Bahl, and A. Ittipiboon, Microstrip Antenna Design Handbook.London: Artech House, 2001.

[11] M. Khodier and C. Christodoulou, "A technique to further increase the bandwidth Of stacked microstrip antennas," in IEEE Antennas and Propagation International Symposium, vol. 3, (Salt Lake City, Utah), pp. 1394-1397, IEEE, July 2000 .

[12] K. Wong and W. Hsu, "A broadband patch antenna with wide slits," in IEEE Antennas and Propagation International Symposium, vol. 3, (Salt Lake City, Utah),pp. 1414- 1417, IEEE, July 2000.

[13] K. F. Lee, K. M. Luk, K. F. Tong, Y. L. Yung, and T. Huynh, "Experimental study of the rectangular patch with a U-shaped slot," in IEEE Antennas and Propagation International Symposium, vol. 1, (Baltimore, Maryland), pp. 10-13, IEEE, July 1996.

[14] Z. M.Chen and Y.W.M. Chial, "Broadband probe-fed Lshaped plate antenna," Microwave and Optical Technology Letters, vol. 26, pp. 204-206, 1985.

[15]A.Shackelford, K. F. Lee, D. Chatterjee, Y. X. Guo, K. M. Luk, and R. Chair, "Smallsize wide bandwidth microstrip patch antennas," in IEEE Antennas and Propagation International Symposium,vol. 1, (Boston, Massachusetts), pp. 86-89, IEEE, July 2001.

[16] C. Balanis, Antenna Theory: Analysis and Design. Toronto: John Wiley and Sons, 2nd ed., 1997. 